\title{
New Polymer Syntheses Part 57: Thermally Stable New Ferrocene-Polyazomethines, Synthetic Methodology, and Characterization
}

\author{
Mona Ahmed Abdel-Rahman, ${ }^{1}$ Mahmoud Ali Hussein,, \\ Kamal Ibrahim Aly, ${ }^{1}$ and Abdelwareth Abdel-Haleam Sarhan ${ }^{1}$ \\ ${ }^{1}$ Polymer Laboratory 122, Chemistry Department, Faculty of Science, Assiut University, Assiut 71516, Egypt \\ ${ }^{2}$ Chemistry Department, Faculty of Science, King Abdulaziz University, P.O. Box 80203, Jeddah 21589, Saudi Arabia
}

Correspondence should be addressed to Mona Ahmed Abdel-Rahman; manoush00@yahoo.com

Received 1 July 2012; Accepted 10 October 2012

Academic Editor: Franck Le Derf

Copyright ( $) 2013$ Mona Ahmed Abdel-Rahman et al. This is an open access article distributed under the Creative Commons Attribution License, which permits unrestricted use, distribution, and reproduction in any medium, provided the original work is properly cited.

\begin{abstract}
A new interesting category of higher thermally stable polyazomethines containing ferrocene in the polymers main chain $\mathbf{6 a - e}$ was synthesized by solution-polycondensation reaction of 1-( $m$-formylphenyl)-1'-(5-formyl-2-methoxyphenyl)-ferrocene monomer 4 with different aliphatic and aromatic diamines. A model compound $\mathbf{5}$ was synthesized from dialdehyde monomer $\mathbf{4}$ with aniline and was characterized by elemental and spectral analyses. The desirable resulting polymers were characterized by elemental and spectral analyses, in addition to solubility measurement using different solvents. The thermal properties of these polymers were evaluated by thermogravimetric analysis (TGA) and differential scanning calorimetry (DSC) measurements. The redox behaviours were studied for the ferrocene polymers in comparison with both the parent ferrocene monomer and the model compound by using cyclic voltammetry $(\mathrm{CV})$.
\end{abstract}

\section{Introduction}

Metal-containing polymers have emerged as an important category of polymeric materials. The impetus for the development of these materials is based on the premise that polymers-containing metals are expected to possess properties significantly different from those of conventional organic polymers. Ferrocene remains, after about 55 years since its discovery, a molecule of intrigue and continued interest. The sustained interest in ferrocene is in part due to the rich chemistry of iron (II) center and the variety of synthetic methods available for functionalizing the cyclopentadienyl ligands [19]. Ferrocene derivatives with good donor abilities (i.e., nitrogen, sulfur, oxygen, phosphorus, etc.) have attracted much interest, as the coordination of a metal to these heteroatoms generates multicenter molecules which have potential in many different areas. Amongst these $\mathrm{N}$-substituted ligands ferrocenyl Schiff bases play pivotal role in the field of catalysis [10-17].
A class of the particularly attractive polymers is the aromatic polyazomethines or Schiff base polymers because they show good mechanical strength, attractive thermal stability and fiber-forming properties [18]. They are synthesized by condensation polymerization of dialdehydes or diketones with diamines to give high-molecular weight polymers. However, poor solubility in organic solvents limited their practical applications in various fields [19]. A few groups of researchers have synthesized soluble polyazomethines by introducing alkyl or alkoxy groups into the polymer chains and investigated their structure and physical properties such as electric conductivity and mechanical properties [20]. In last years, there has been increasing interest in the synthesis of new polymers with unusual thermal, optical, and mechanical properties. Among these ones, polyazomethines were investigated with respect to their properties including thermal stability [21], optical and electrical response [22-25], conductivity [26, 27], syn-anti isomerization [28], opto(electronic) and liquid crystal properties [29-31], and film or fiber 
forming ability [32, 33]. The inclusion of ferrocene units into polymeric arrays has attracted much attention due to the electronic donating ability, reversible redox chemistry, steric properties, and ready functionalization of this stable fragment.

The approach chosen in this study deals with the synthesis and characterization of new polyazomethines containing ferrocene moiety in the polymers main chain. The electrochemical behaviours of these polymers were investigated by cyclic voltammetry. Moreover solubility, thermal stability, and morphology of the synthesized polymers had been examined and the data were discussed.

\section{Experimental Part}

2.1. Materials. All polymers are new; details of the synthesis and characterization of these compounds are given in the experimental part. All ferrocene monomers were prepared following the previously reported methods [34]. Dichloromethane (DCM) and chloroform from El-Nasr Chemical Company (Egypt) were freshly distilled before use: propane-1,3-diamine (>99\%) Merck, decane-1,10-diamine (>96\%) Merck, dodecane-1,12-diamine (>98\%) Merck, $p$ phenylenediamine (>98\%) Merck, and $4,4^{\prime}$-diaminodiphenyl ether (>98\%) Merck. Reagents and solvents were purchased and used as received unless otherwise stated. All reactions were performed under nitrogen atmosphere. Silica gel $60 \mathrm{M}$ (Macherey-Nagel, 0.04-0.063 mm/230-400 mesh) was used as a stationary phase for column chromatography. Whenever possible, reactions were monitored by thin-layer chromatography (TLC) using TLC silica gel coated aluminum plates $60 \mathrm{~F}_{254}$ (Merck).

2.2. Instrumentation. Fourier transform Infrared spectrophotometer (FT-IR) spectra were recorded on Nicolet 6700Thermo Fisher Scientific, by using the $\mathrm{KBr}$ pellet technique. ${ }^{1} \mathrm{H}$-NMR spectra were recorded on a Bruker AM $200\left({ }^{1} \mathrm{H}: 200 \mathrm{MHz}\right)$ spectrometer, and chemical shifts are reported as $\delta$ values (ppm) relative to internal $\mathrm{Me}_{4} \mathrm{Si}$. Highresolution MALDI-TOF mass spectrometry (MS) analysis was performed by the MS-service of the Laboratorium für Organische Chemie at ETH Zürich. Elemental analyses were performed by the Mikrolabor of the Laboratorium für Organische Chemie, ETH Zürich. The samples were dried rigorously under vacuum prior to analysis to remove stronglyadhering solvent molecules. High-resolution thermogravimetric analysis (TGA) was performed on a Q500 thermogravimetric analyzer (TA Instruments, New Castle, DE, USA) and differential thermal gravimetric (DTG) were carried out in air with Shimadzu DTG-60 at heating rate of $10^{\circ} \mathrm{C} / \mathrm{min}$ in air. All measurements were carried out in an air-stream under the same conditions. The mass loss was plotted against increasing temperature as well as its first derivative (DTG) that represents the change in decomposition rate. Differential scanning calorimetry (DSC) measurements were performed using the DSC Q1000 differential scanning calorimeter from TA Instruments in a temperature range of $-80-+200^{\circ} \mathrm{C}$ with a heating rate of $10^{\circ} \mathrm{C} \mathrm{min}^{-1}$. Samples of a total weight ranging between 3 and $10 \mathrm{mg}$ were closed into aluminum pans of $40 \mu \mathrm{L}$, covered by a holed cap, and analyzed under a nitrogen atmosphere. The glass transition temperature $\left(T_{g}\right)$ was taken in the second heating run. CV was measured on a cyclic voltammetric analyzer using glassy carbon electrode (GCE), Bioanalytical System, USA, starting potential $0.0 \mathrm{~V}$ and final potential $+1.5 \mathrm{~V}$, at Analytical Chemistry Unit ACAL, Assiut University, Egypt.

\subsection{Monomers Syntheses}

2.3.1. 1-(m-Formylphenyl)-1'-(5-formyl-2-methoxphenyl)ferrocene (4). Monomer 4 was synthesized in our previous work [34] as follows. A mixture of ferrocene-dialcohols 3 (3.00 g, $6.70 \mathrm{mmol})$ and $\mathrm{MnO}_{2}(30.00 \mathrm{~g})$ in $\mathrm{CHCl}_{3}$ was stirred at room temperature for $15 \mathrm{~h}$. The reaction mixture was filtered off through glass wool and the filtrate was evaporated under reduced pressure at $30^{\circ} \mathrm{C}$. The product was purified by column chromatography on silica gel $\left(\mathrm{CHCl}_{3}\right.$ : hexane, $3: 1$ ratio) as orange red crystals: $71 \%$; m.p.: $87-88^{\circ} \mathrm{C}$.

$\mathrm{C}_{25} \mathrm{H}_{20} \mathrm{FeO}_{3}$ : Calcd. C, 70.77; H, 4.75; Found. C, 71.01; $\mathrm{H}, 4.51$. FT-IR (KBr): $v \mathrm{C}=\mathrm{O} 1702 \mathrm{~cm}^{-1} \cdot{ }^{1} \mathrm{H}-\mathrm{NMR}\left(\mathrm{CDCl}_{3}\right)$ : $\delta=3.81\left(\mathrm{~s}, 3 \mathrm{H}, \mathrm{OCH}_{3}\right), 4.32(\mathrm{~s}, 2 \mathrm{H}$, ferrocene- $\mathrm{H}), 4.36(\mathrm{~s}$, $2 \mathrm{H}$, ferrocene- $\mathrm{H}), 4.61$ (s, $2 \mathrm{H}$, ferrocene- $\mathrm{H}), 4.82(\mathrm{~s}, 2 \mathrm{H}$, ferrocene- $\mathrm{CH}), 6.67(\mathrm{~m}, 1 \mathrm{H}, \mathrm{Ar}-\mathrm{H}), 7.18-7.62$ (m, 6H, Ar$\mathrm{H}), 9.7$ (s, 1H, CHO), 9.8 (s, 1H, CHO). FABMS m/e (\%) [ $\mathrm{M}^{+}$, 424].

\subsection{Model Compound Synthesis}

2.4.1. 1-(m-anilinemethinephenyl)-1'-(2-methoxy-5-anilinemethinephenyl)ferrocene (5). A mixture of 1-( $m$-formylphenyl)-1'-(5-formyl-2-methoxphenyl)ferrocene (4) (0.424 g, $1.000 \mathrm{mmol})$ and aniline $(0.245 \mathrm{~g}, 2.200 \mathrm{mmol})$ was dissolved in $30 \mathrm{~mL}$ absolute $\mathrm{EtOH}$ in presence of few drops piperidine. The reaction mixture was stirred in oil bath at $80^{\circ} \mathrm{C}$ under nitrogen for $6 \mathrm{~h}$. A solid product separated out during reflux, which was filtered off and dried. Purification by recrystallization from ethanol as orange red crystals yield: 75\%; m.p.: $114-116^{\circ} \mathrm{C}$.

$\mathrm{C}_{37} \mathrm{H}_{30} \mathrm{FeN}_{2} \mathrm{O}$ : Calcd. C, 77.35; H, 5.26; N, 4.88; Found: C, 77.04; H, 5.94; N, 5.00. FT-IR (KBr): $v \mathrm{CH}=\mathrm{N} 1622 \mathrm{~cm}^{-1} .{ }^{1} \mathrm{H}-$ $\mathrm{NMR}\left(\mathrm{CDCl}_{3}\right): \delta=3.89\left(\mathrm{~s}, 3 \mathrm{H}, \mathrm{OCH}_{3}\right), 4.31(\mathrm{t}, 2 \mathrm{H}$, ferrocene$\mathrm{CH}), 4.35(\mathrm{t}, 2 \mathrm{H}$, ferrocene- $\mathrm{CH}), 4.64(\mathrm{t}, 2 \mathrm{H}$, ferrocene- $\mathrm{CH})$, $4.85(\mathrm{t}, 2 \mathrm{H}$, ferrocene- $\mathrm{CH}), 6.71(\mathrm{~d}, 4 \mathrm{H}, \mathrm{Ar}-\mathrm{H}), 6.74(\mathrm{~d}, 4 \mathrm{H}$, Ar-H), 7.16-7.45 (m, 3H, Ar-H), 7.63 (d, 4H, Ar-H), 7.67 (d, $4 \mathrm{H}, \mathrm{Ar}-\mathrm{H}), 7.82$ (d, 2H, Ar-H), $8.26(\mathrm{~s}, 1 \mathrm{H}, \mathrm{CH}=\mathrm{N}), 8.31$ (s, $1 \mathrm{H}, \mathrm{CH}=\mathrm{N})$. MS (MALDI-TOF): $m / z=575.17[\mathrm{M}]^{+}$.

\subsection{Polymer Syntheses}

2.5.1. General Procedure. In a three-necked flask equipped with a condenser, dry nitrogen inlet, outlet, and dropping funnel, a mixture of 1-( $m$-formylphenyl)-1 ${ }^{\prime}$-(5-formyl2-methox-phenyl)ferrocene (4) $(1.0 \mathrm{mmol})$ and diamine $(1.1 \mathrm{mmol})$ was dissolved in $30 \mathrm{~mL}$ absolute $\mathrm{EtOH}$ in presence of few drops piperidine. The reaction mixture was stirred in an oil bath at $80^{\circ} \mathrm{C}$ under nitrogen for $6-10 \mathrm{~h}$. A solid product 
separated out during reflux, which was filtered off, washed well with hot ethanol, was dried under high vacuum.

Fc-Polyazomethine $\mathbf{6 a}$. The title compound was synthesized according to general procedure of polymerization from compound $4(0.424 \mathrm{~g}, 1.000 \mathrm{mmol})$, propane-1,3-diamine $(0.081 \mathrm{~g}$, $1.100 \mathrm{mmol}$ ), and piperidine (few drops) in absolute $\mathrm{EtOH}$ $(30 \mathrm{~mL})\left(6 \mathrm{~h}\right.$ at $\left.80^{\circ} \mathrm{C}\right)$ as an orange precipitate $(68 \%)$.

$\mathrm{C}_{28} \mathrm{H}_{26} \mathrm{FeN}_{2} \mathrm{O}$ : Calcd. C, 72.73; H, 5.67; N, 6.06; found: C, 73.72; $\mathrm{H}, 5.56 ; \mathrm{N}, 5.96$. FT-IR (KBr): $v \mathrm{CH}=\mathrm{N} 1642 \mathrm{~cm}^{-1} .{ }^{1} \mathrm{H}-$ $\operatorname{NMR}\left(\mathrm{CDCl}_{3}\right): \delta=1.50\left(\mathrm{q}, 2 \mathrm{H}, \mathrm{CH}_{2}\right), 3.73\left(\mathrm{t}, 4 \mathrm{H}, \mathrm{CH}_{2}\right), 3.78$ $\left(\mathrm{s}, 3 \mathrm{H}, \mathrm{OCH}_{3}\right), 4.17-4.70(\mathrm{~m}, 8 \mathrm{H}$, ferrocene- $\mathrm{H}), 6.60-8.13(\mathrm{~m}$, $9 \mathrm{H}, \mathrm{Ar}-\mathrm{H} \& \mathrm{CH}=\mathrm{N})$.

Fc-Polyazomethine $\mathbf{6} \boldsymbol{b}$. The title compound was synthesized according to general procedure of polymerization from compound $4(0.424 \mathrm{~g}, 1.000 \mathrm{mmol})$, decane-1,10-diamine $(0.189 \mathrm{~g}$, $1.100 \mathrm{mmol}$ ), and piperidine (few drops) in absolute $\mathrm{EtOH}$ $(30 \mathrm{~mL})\left(6 \mathrm{~h}\right.$ at $\left.80^{\circ} \mathrm{C}\right)$ as an orange film $(74 \%)$.

$\mathrm{C}_{35} \mathrm{H}_{40} \mathrm{FeN}_{2} \mathrm{O}$ : Calcd. C, 74.99; H, 7.19; N, 5.00; found: C, 72.19; H, 6.96; N, 4.81. FT-IR (KBr): $v \mathrm{CH}=\mathrm{N} 1644 \mathrm{~cm}^{-1} .{ }^{1} \mathrm{H}-$ $\operatorname{NMR}\left(\mathrm{CDCl}_{3}\right): \delta=1.30\left(\mathrm{t}, 16 \mathrm{H}, \mathrm{CH}_{2}\right), 3.57\left(\mathrm{q}, 4 \mathrm{H}, \mathrm{CH}_{2}\right), 3.79$ $\left(\mathrm{s}, 3 \mathrm{H}, \mathrm{OCH}_{3}\right), 4.27-4.77(\mathrm{~m}, 8 \mathrm{H}$, ferrocene- $\mathrm{H}), 6.68-8.16(\mathrm{~m}$, $9 \mathrm{H}, \mathrm{Ar}-\mathrm{H} \& \mathrm{CH}=\mathrm{N})$.

Fc-Polyazomethine $\mathbf{6 c}$. The title compound was synthesized according to general procedure of polymerization from compound 4 (0.424 g, $1.000 \mathrm{mmol})$, dodecane-1,12-diamine $(0.220 \mathrm{~g}, 1.100 \mathrm{mmol})$, and piperidine (few drops) in absolute $\mathrm{EtOH}(30 \mathrm{~mL})\left(6 \mathrm{~h}\right.$ at $\left.80^{\circ} \mathrm{C}\right)$ as a reddish brown precipitate (73\%).

$\mathrm{C}_{37} \mathrm{H}_{44} \mathrm{FeN}_{2} \mathrm{O}$ : Calcd. C, 75.50; H, 7.53; N, 4.76; found: C, 71.98; H, 7.84; N, 5.05. FT-IR (KBr): $v \mathrm{CH}=\mathrm{N} 1646 \mathrm{~cm}^{-1}$.

Fc-Polyazomethine $\mathbf{6} \boldsymbol{d}$. The title compound was synthesized according to general procedure of polymerization from compound $4(0.424 \mathrm{~g}, 1.000 \mathrm{mmol})$, $p$-phenylenediamine $(0.118 \mathrm{~g}$, $1.100 \mathrm{mmol}$ ), and piperidine (few drops) in absolute $\mathrm{EtOH}$ $(30 \mathrm{~mL})\left(10 \mathrm{~h}\right.$ at $\left.80^{\circ} \mathrm{C}\right)$ as an orange precipitate $(65 \%)$.

$\mathrm{C}_{31} \mathrm{H}_{24} \mathrm{FeN}_{2} \mathrm{O}$ : Calcd. C, 75.01; H, 4.87; N, 5.64; found: C, 73.81; H, 4.99; N, 5.61. FT-IR (KBr): $v \mathrm{CH}=\mathrm{N} 1619 \mathrm{~cm}^{-1}$.

Fc-Polyazomethine $\mathbf{6 e}$. The title compound was synthesized according to general procedure of polymerization from compound $4(0.424 \mathrm{~g}, 1.000 \mathrm{mmol}), 4,4^{\prime}$-diaminodiphenyl ether $(0.118 \mathrm{~g}, 1.100 \mathrm{mmol})$, and piperidine (few drops) in absolute $\mathrm{EtOH}(30 \mathrm{~mL})\left(10 \mathrm{~h}\right.$ at $\left.80^{\circ} \mathrm{C}\right)$ as an orange precipitate $(69 \%)$.

$\mathrm{C}_{37} \mathrm{H}_{28} \mathrm{FeN}_{2} \mathrm{O}_{2}$ : Calcd. C, 75.52; H, 4.80; N, 4.76; found: C, 74.25; H, 5.33; N, 5.09. FT-IR (KBr): $v \mathrm{CH}=\mathrm{N} 1621 \mathrm{~cm}^{-1}$, ${ }^{1} \mathrm{H}-\mathrm{NMR}\left(\mathrm{CDCl}_{3}\right): \delta=3.75\left(\mathrm{~s}, 3 \mathrm{H}, \mathrm{OCH}_{3}\right), 4.34-4.97(\mathrm{~m}, 8 \mathrm{H}$, ferrocene-H), 6.43-7.79 (m, 15H, Ar-H), $8.09(\mathrm{~s}, 2 \mathrm{H}, \mathrm{CH}=\mathrm{N})$.

\section{Results and Discussion}

3.1. Monomers Syntheses. The synthetic sequences to monomers 2-4 are delineated in Scheme 1 as done in our previous work [34]. Appling Gomberg's arylation of ferrocene with diazonium salt of the methyl 3-amino4-methoxybenzoate to give the corresponding 1-(3methoxycarbonyl-2-methoxyphenyl)ferrocene which was subjected to diazotization with diazonium salt, derived from methyl 3-aminobenzoate, to give the corresponding diester 2 then reduction with Lithium aluminium hydride (LAH) to give monomer 3 , which was oxidized with activated $\mathrm{MnO}_{2}$ in dry $\mathrm{CHCl}_{3}$ to get the target monomer 1- $(\mathrm{m}-$ formylphenyl)-1' -(5-formyl-2-methoxyphenyl)ferrocene (4), in $71 \%$ yield.

3.2. Synthesis of Model Compound. Before attempting polymerization, model compound $\mathbf{5}$ was synthesized by the interaction of 1 mole of monomer 4 with 2 moles of aniline in $\mathrm{EtOH}$, piperidine as described in Scheme 2. The structure of this model compound was confirmed by elemental and spectral analysis. The FT-IR spectrum showed a new characteristic absorption band at $1622 \mathrm{~cm}^{-1}$ due to $\mathrm{CH}=\mathrm{N}$ stretching in addition to other characteristic absorption bands of the $\mathrm{Fe}-\mathrm{Cp}$ stretching vibrations, at 1074, 975 and $823 \mathrm{~cm}^{-1}$. The ${ }^{1} \mathrm{H}$-NMR spectrum of model compound 5 (in $\mathrm{CDCl}_{3}$ ) was in accordance with the proposed structure (Figure 1). It showed the molecular ion peak in the matrixassisted laser desorption/ionization time-of-flight (MALDITOF) mass spectrum.

3.3. Polymerization and Polymer Characterization. Using solution polycondensation technique [35] by the interaction of one mole of monomer 4 with one mole of diamine compounds in presence of few drops piperidine give new Fcpolyazometines $\mathbf{6 a}-\mathbf{e}$ as described in Scheme 3.

The structures of the resulting polymers were also established from elemental analyses and spectral data. The elemental analyses of all the polymers coincided with the characteristic repeating units of each polymer; the data are included in the experimental part. The FT-IR spectral data of all polyazomethine derivatives showed characteristic absorption band at $3078-3085 \mathrm{~cm}^{-1}$ for $\mathrm{C}-\mathrm{H}$ aromatic, at $2833-$ $2926 \mathrm{~cm}^{-1}$ for C-H aliphatic $1619-1646 \mathrm{~cm}^{-1}$ due to $\mathrm{C}=\mathrm{N}$, bands of the $\mathrm{Fe}-\mathrm{Cp}$ stretching vibrations at 1079, 970 and $815 \mathrm{~cm}^{-1}$. In addition, other characteristic absorption bands due to specific groups present in the various polymers. Also the ${ }^{1} \mathrm{H}-\mathrm{NMR}$ spectra of Fc-polyazomethine $\mathbf{6 a}, \mathbf{6} \mathbf{b}$, and $\mathbf{6 e}$ (in $\mathrm{CDCl}_{3}$ ) were in accordance with the proposed structures (Figure 2, ${ }^{1} \mathrm{H}$-NMR of Fc-polyazomethine $\mathbf{6 b}$ ).

3.4. Solubility. The solubility of the Fc-polyazomethines $\mathbf{6 a}-$ d was tested using solvents including dimethyl sulfoxide (DMSO), dimethyl formamide (DMF), chloroform, benzene, hexane, and formic acid. $50 \mathrm{mg}$ of the polymer were added to $1 \mathrm{~mL}$ of the chosen solvent and the solution analyzed by visual inspection. The results are shown in Table 1. All Fcpolyazometines $\mathbf{6 a - e}$ are clearly less soluble in polar, aprotic solvents DMSO and DMF except Fc-polyazomethines which contain aliphatic moieties $\mathbf{6 a - c}$ are virtually insoluble in DMSO. All Fc-polyazomethines $\mathbf{6 a - e}$ are soluble in hexane and formic acid. 


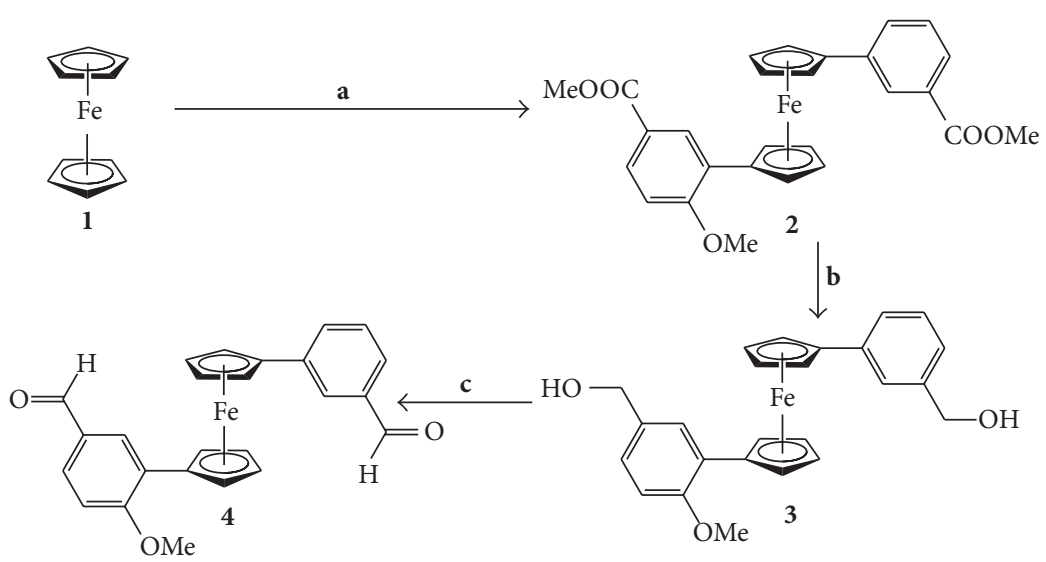

Scheme 1: Synthesis procedure of ferrocene monomer 4. Reagents and conditions: a (i) diazonium salt of methyl 3-amino-4methoxybenzoate, $\mathrm{AcOH}$ (ii) diazonium salt of methyl 3-aminobenzoate; b LAH, EtOH, r.t.; $\mathbf{c} \mathrm{MnO}_{2}, \mathrm{CHCl}_{3}$, r.t.



SCHEME 2: Synthesis procedure of model compound 5. Reagents and conditions: (a) EtOH, piperidine, reflux.

TABLE 1: Room-temperature solubility characteristics of Fc-polyazomethines $\mathbf{6 a}, \mathbf{6 b}, \mathbf{6 c}, \mathbf{6 d}$, and $\mathbf{6 e}$.

\begin{tabular}{lcccccc}
\hline $\begin{array}{l}\text { Polymer } \\
\text { number }\end{array}$ & DMF & DMSO & $\mathrm{CHCl}_{3}$ & Benzene & Hexane & $\mathrm{HCOOH}$ \\
\hline $\mathbf{6 a}$ & + & - & ++ & ++ & ++ & ++ \\
$\mathbf{6 b}$ & + & - & ++ & ++ & ++ & ++ \\
$\mathbf{6 c}$ & + & - & + & ++ & ++ & ++ \\
$\mathbf{6 d}$ & + & + & + & + & ++ & ++ \\
$\mathbf{6 e}$ & + & + & ++ & + & ++ & ++ \\
\hline
\end{tabular}

++ : soluble according to visual inspection, + : partially soluble, - : insoluble.

All Fc-polyazomethines which contain aliphatic moieties $\mathbf{6 a}-\mathbf{c}$ are freely soluble in chloroform and benzene except $\mathbf{6 c}$ which is partially soluble in chloroform. All Fcpolyazomethines which contain aromatic moieties $\mathbf{6 d - e}$ are partially soluble in chloroform and benzene except $\mathbf{6 e}$ which is freely soluble in chloroform. The study succeeded in inserting the ferrocene moieties in the polymer main chain. As expected, the presence of such moieties in the polymer
TABLE 2: Thermal properties of Fc-polyazomethines $\mathbf{6 a}, \mathbf{6 b}, \mathbf{6 c}, \mathbf{6 d}$, and $6 \mathbf{e}$.

\begin{tabular}{lcccccc}
\hline Polymer & \multicolumn{6}{c}{ Temperature $\left({ }^{\circ} \mathrm{C}\right)$ for various decomposition levels* } \\
number & $10 \%$ & $20 \%$ & $30 \%$ & $40 \%$ & $50 \%$ & PDT $_{\max }$ \\
\hline 6a & 140 & 170 & 385 & 430 & 440 & 439 \\
6b & 430 & 430 & 431 & 432 & 433 & 433 \\
6c & 435 & 450 & 455 & 480 & 510 & 516 \\
6d & 340 & 340 & 345 & 350 & 370 & 373 \\
6e & 395 & 396 & 397 & 398 & 400 & 402 \\
\hline${ }^{*}$ The values were determined by TGA at heating rate of $10^{\circ} \mathrm{C} \mathrm{min}^{-1}$.
\end{tabular}

backbone will lead to increasing chain packing distances and decreasing interchain interactions, such as hydrogen bonding, thereby increasing the solubility compared with other polyazomethines [36]. It can be clarified that the solubility of Fc-polyazomethines 6a-e is based on the aliphatic or aromatic spacers in the polymer backbone. It was found that the presence of aliphatic spacers in the polymer backbone increase the flexibility of the polymer chains and allow the solvent molecules to go through them which increase the probability of solubility.

3.5. TGA and DSC Studies. The thermal behaviour of the Fc-polyazomethines $\mathbf{6 a}-\mathbf{d}$ was evaluated by TGA in air with heating rate of $10^{\circ} \mathrm{C} / \mathrm{min}$. TGA curves show a small weightloss in the range $0.5-4.5 \%$ starting at $50^{\circ} \mathrm{C}$ until $235^{\circ} \mathrm{C}$ except Fc-polyazomethine 6a. Table 2 shows the temperatures for the various \% weight loss. The initial decomposition of these polymers ( $10 \%$ loss) is considered to be polymerdecomposition temperature (PDT) [35], which occurred in range $140^{\circ} \mathrm{C}$ to $435^{\circ} \mathrm{C}$. The maximum polymer degradation temperature $\left(\mathrm{PDT}_{\max }\right)$ corresponds to the temperature at which the maximum rate of weight loss occurred. $\mathrm{PDT}_{\max }$ for Fc-polyazomethines $6 \mathbf{a}-\mathbf{d}$ were $439^{\circ} \mathrm{C}, 432^{\circ} \mathrm{C}, 516^{\circ} \mathrm{C}, 373^{\circ} \mathrm{C}$, and $402^{\circ} \mathrm{C}$, respectively. The degradation steps involve the scission of azomethine groups; scission of many bonds with the liberation of free shorter chains depending upon the 


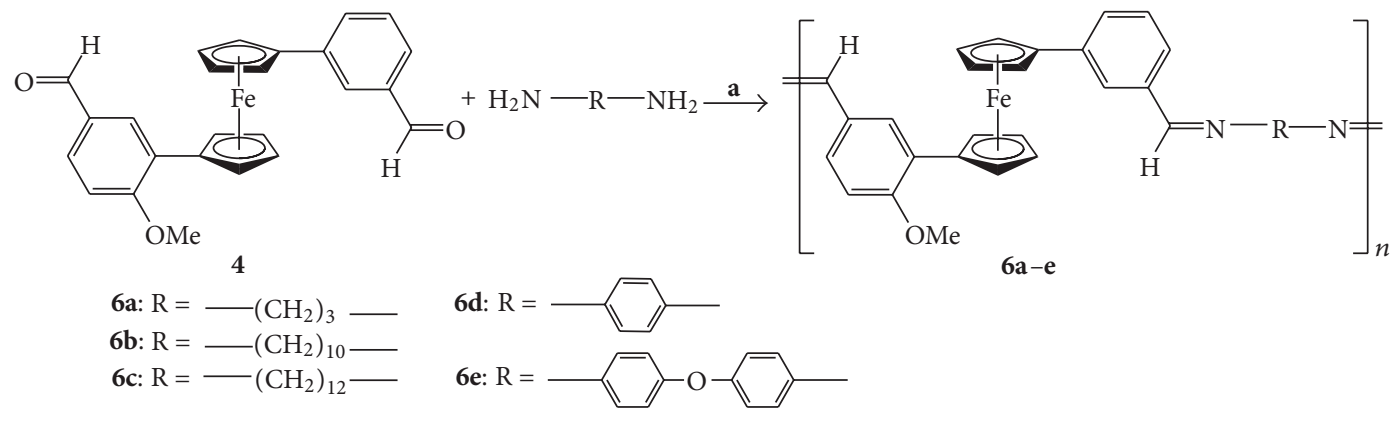

SCHEME 3: Synthesis procedure of Fc-polyazomethines 6a-e. Reagents and conditions: (a) EtOH, piperidine, reflux.

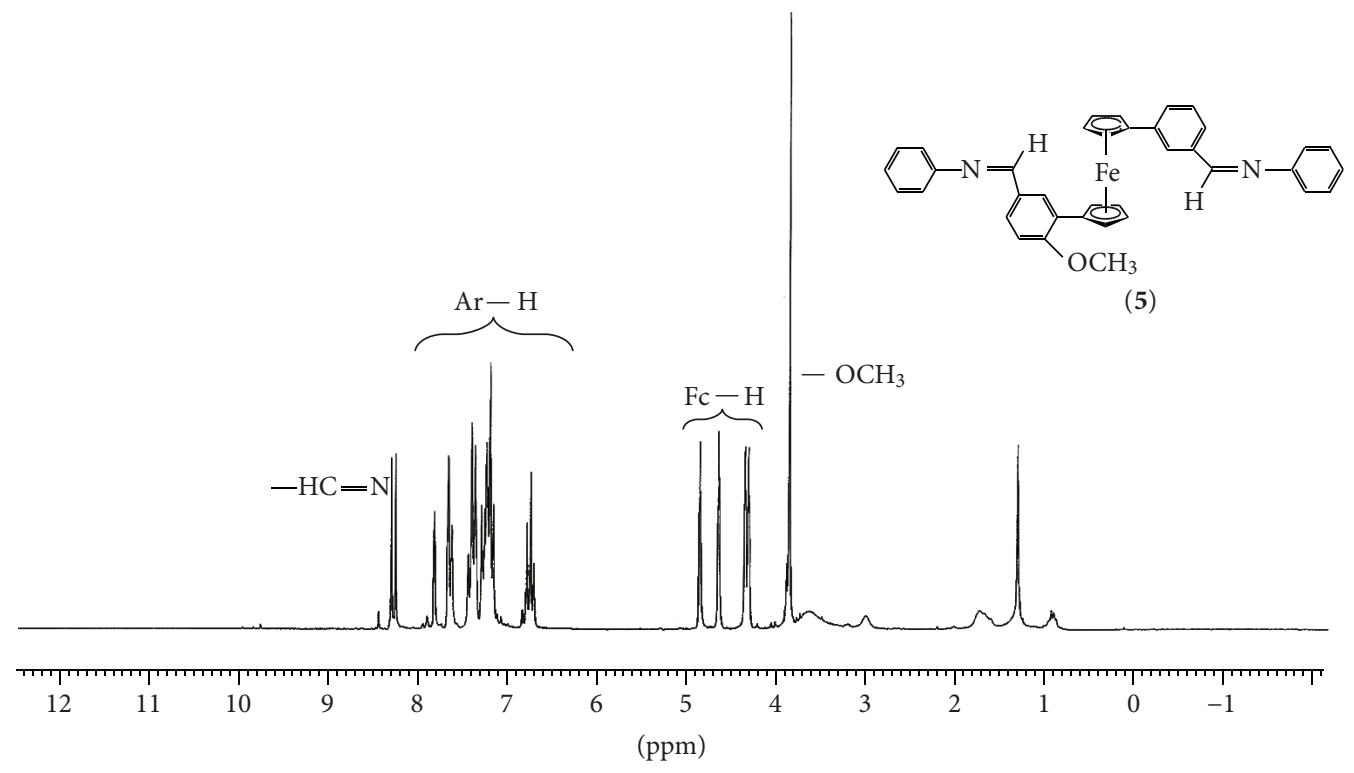

Figure 1: ${ }^{1} \mathrm{H}$-NMR spectrum of model compound 5 in $\mathrm{CDCl}_{3}$.

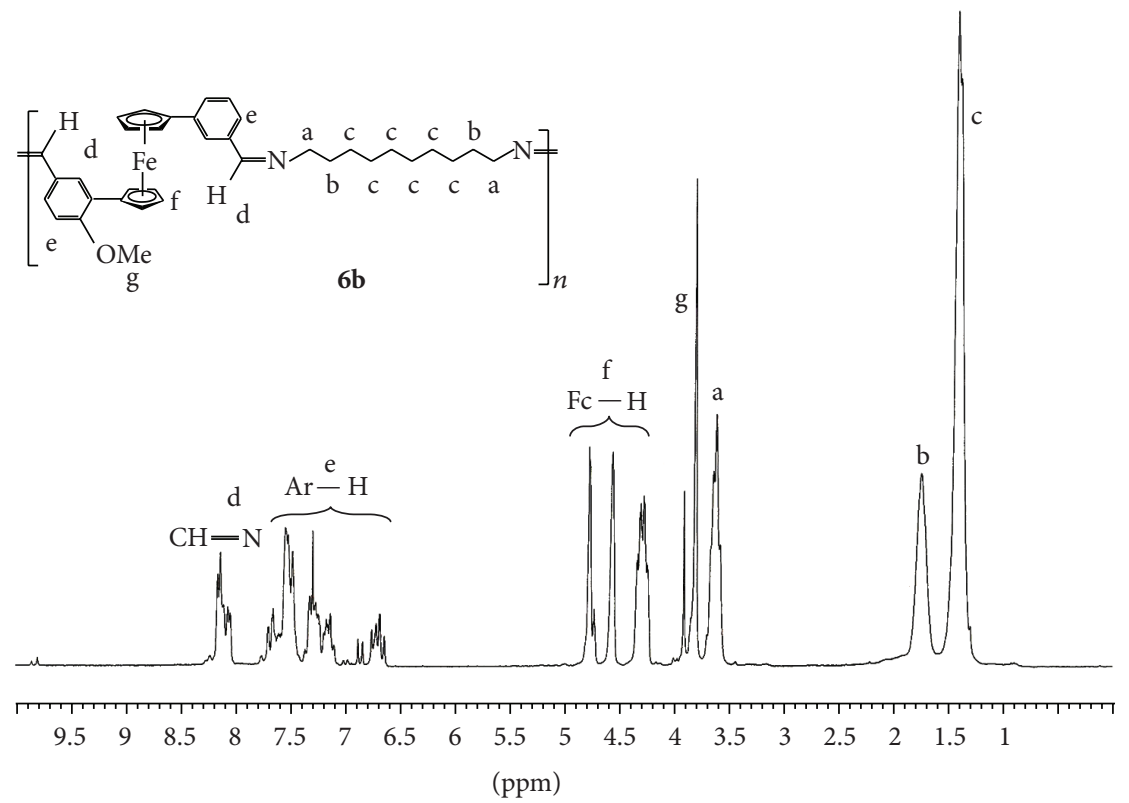

FIGURE 2: ${ }^{1} \mathrm{H}$-NMR spectrum of Fc-polyazomethine $\mathbf{6} \mathbf{b}$ in $\mathrm{CDCl}_{3}$. 


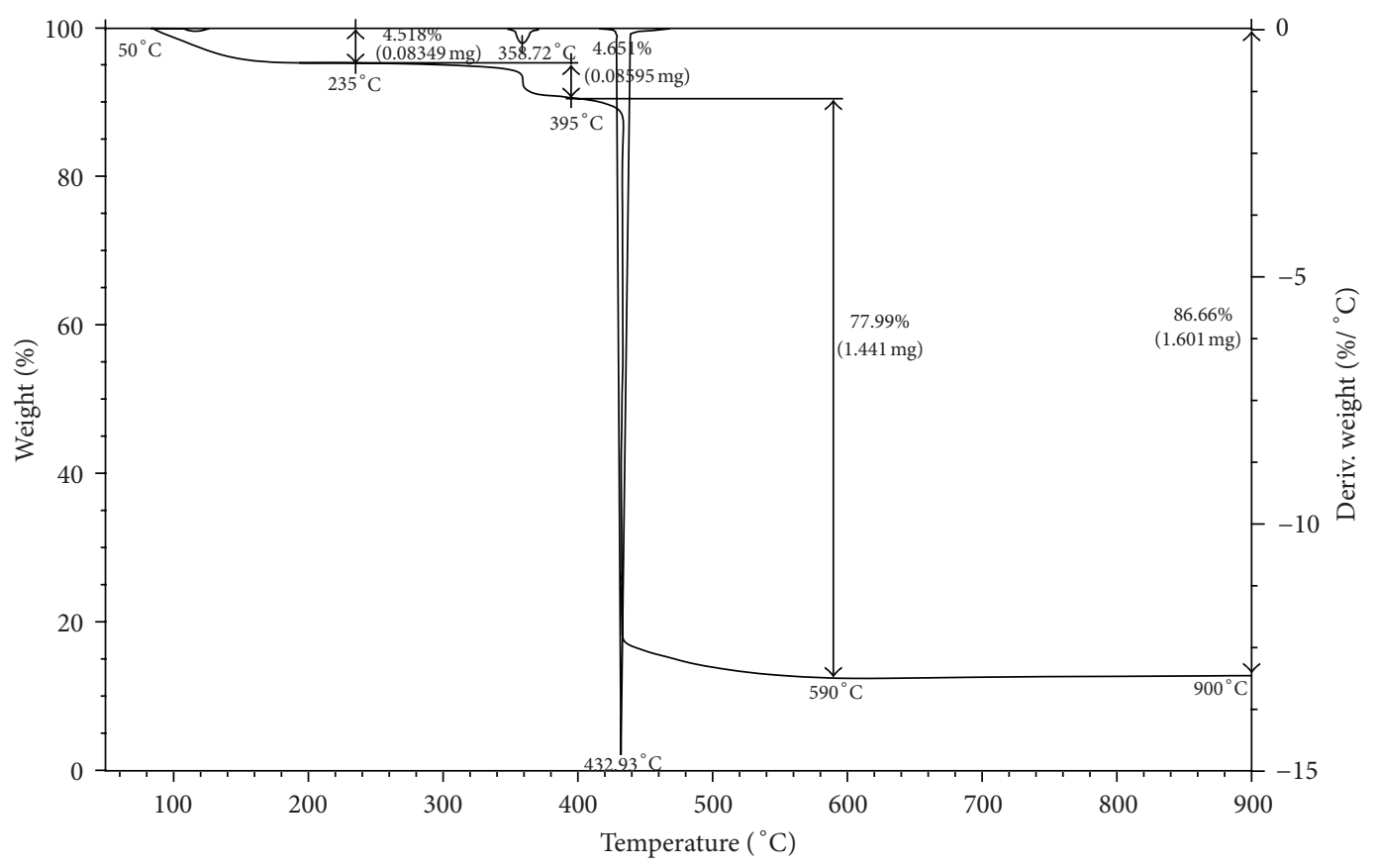

FIGURE 3: TGA curve of Fc-polyazomethine $\mathbf{6 b}$.

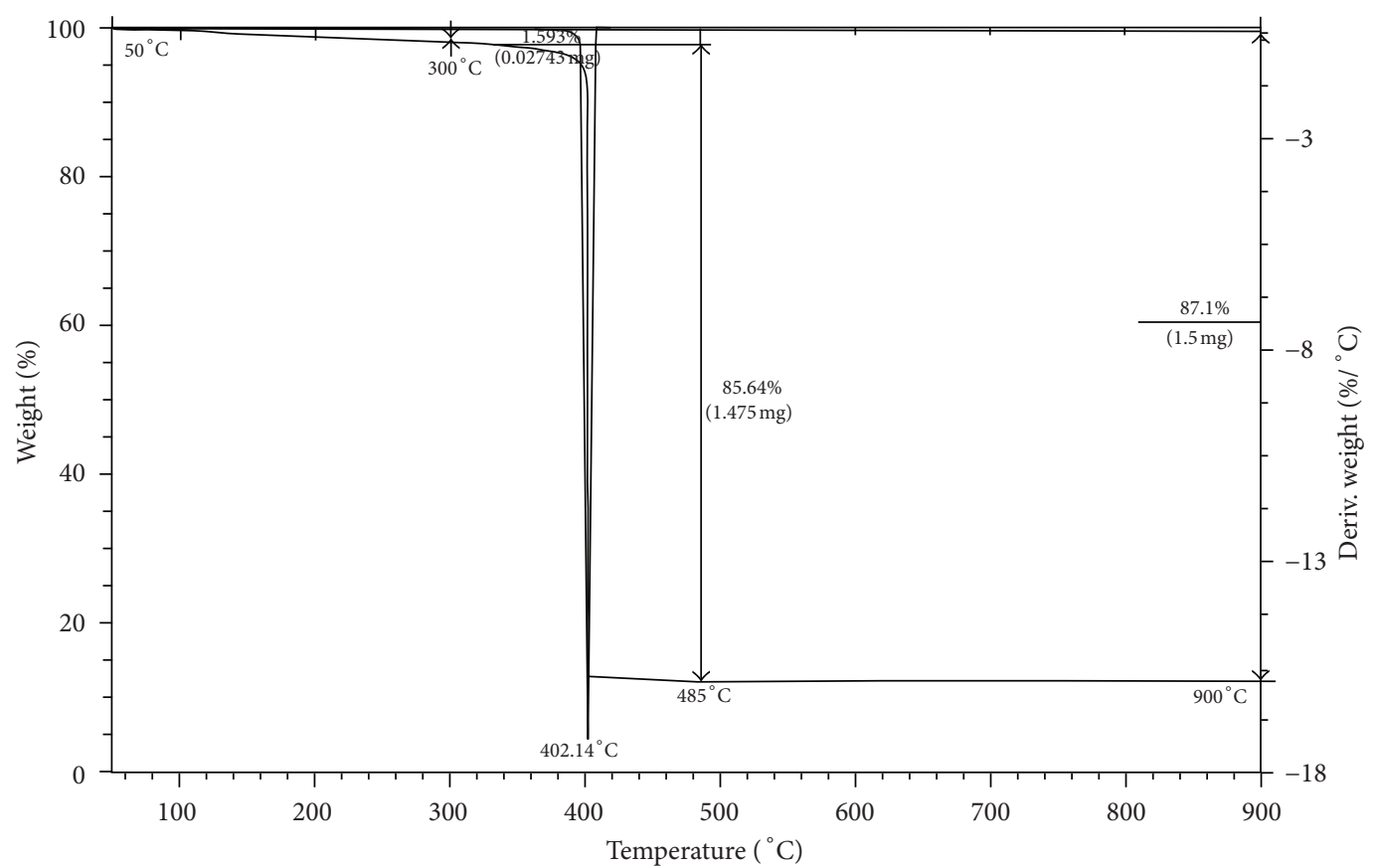

Figure 4: TGA curve of Fc-polyazomethine 6 e. 
TABLE 3: Cyclic voltammetric parameters of monomer 4, model compound 5, Fc-polyazomethines $\mathbf{6 a}, \mathbf{6 b}, \mathbf{6 c}, \mathbf{6 d}$, and $\mathbf{6 e}$ at $20 \mathrm{mVs}{ }^{-1}$.

\begin{tabular}{lccccccccccccc}
\hline \multirow{2}{*}{ Compound number } & \multicolumn{2}{c}{$E_{\mathrm{pc}}(\mathrm{mv})$} & \multicolumn{2}{c}{$E_{\mathrm{pa}}(\mathrm{mv})$} & \multicolumn{2}{c}{$E(\mathrm{mv})$} & \multicolumn{2}{c}{$\Delta E_{p}(\mathrm{mv})$} & \multicolumn{2}{c}{$I_{\mathrm{pc}}(\mu \mathrm{A})$} & $I_{\mathrm{pa}}(\mu \mathrm{A})$ \\
& $P_{1}$ & $P_{2}$ & $P_{1}$ & $P_{2}$ & $P_{1}$ & $P_{2}$ & $P_{1}$ & $P_{2}$ & $P_{1}$ & $P_{2}$ & $P_{1}$ & $P_{2}$ \\
\hline $\mathbf{4}$ & 249 & - & 437 & 637 & 343 & - & 188 & - & +1.98 & - & -0.79 & -2.14 \\
$\mathbf{5}$ & 346 & - & 480 & 565 & 413 & - & 134 & - & +7.40 & - & -11.27 & -44.18 \\
$\mathbf{6 a}$ & 303 & - & 467 & 540 & 385 & - & 164 & - & +1.64 & - & -7.58 & -5.53 \\
$\mathbf{6 b}$ & 303 & - & 467 & - & 385 & - & 164 & - & +2.89 & - & -13.28 & - \\
$\mathbf{6 c}$ & 346 & - & 510 & - & 428 & - & 164 & - & +1.62 & - & -4.40 & - \\
$\mathbf{6 d}$ & 358 & - & 528 & 619 & 443 & - & 170 & - & +3.63 & - & -9.24 & -10.72 \\
$\mathbf{6 e}$ & 382 & - & 419 & 643 & 401 & - & 37 & - & +8.67 & - & -2.40 & -43.54 \\
\hline
\end{tabular}

nature of these polymers. This observation is in agreement with that observed in the literature [26]. TGA curve for Fc-polyazomethine 6a shows mass loss between 127.62 and $250.94^{\circ} \mathrm{C}(-17.03 \%)$ in first region, between 253.42 and $367.82^{\circ} \mathrm{C}(-5.90 \%)$ in the second region, and between 367.87 and $505.51^{\circ} \mathrm{C}(-58.11 \%)$ in third region. Fc-Polyazomethine 6b shows mass loss between 358.72 and $395.00^{\circ} \mathrm{C}(-4.65 \%)$ in first region, between 395.00 and $432.93^{\circ} \mathrm{C}(-77.99 \%)$ in the second region (Figure 3 ). Fc-Polyazomethine $6 \mathrm{c}$ shows mass loss between 219.40 and $403.31^{\circ} \mathrm{C}(-5.56 \%)$ in first region, between 404.77 and $473.25^{\circ} \mathrm{C}(-28.67 \%)$ in the second region, and between 474.23 and $569.60^{\circ} \mathrm{C}(-50.21 \%)$ in third region. Fc-Polyazomethine $\mathbf{6 d}$ shows mass loss between 227.61 and $340.74^{\circ} \mathrm{C}(-37.77 \%)$ in first region, between 339.76 and $447.43^{\circ} \mathrm{C}(-46.38 \%)$ in the second region. Fc-Polyazomethine 6e shows mass loss between 300.00 and $485.00^{\circ} \mathrm{C}(-85.64 \%)$ in one region (Figure 4). From the TGA data it is noticed that the fast degradation step in all Fc-polyazomethines $\mathbf{6 a - e}$ did not start before $277.61^{\circ} \mathrm{C}$. Thus, it is quite acceptable to claim that these polymers are thermally stable till high temperature.

The thermal behaviour of two selected polymers, Fcpolyazomethine $\mathbf{6 b}$ and $\mathbf{6 e}$ as containing different aliphatic and aromatic spacers in the main chain was studied by differential scanning calorimetry (DSC) which revealed that these compounds have $T_{g}$ values at $55^{\circ} \mathrm{C}$ and $150^{\circ} \mathrm{C}$, respectively, indicating that $\mathrm{Fc}$-polyazomethine containing aromatic spacers has higher $T_{g}$ values than that which contains aliphatic spacers and this may be due to the more flexibility effect of the aliphatic spacers on the polymer chains.

3.6. Electrochemical Study. The electrochemical behaviours of some ferrocene derivatives were investigated by cyclic voltammetry showing interesting behaviour $[34,37,38]$, this encouraged us to study the electrochemical behaviour of some new polyazomethines with ferrocene moiety in the main chain. The electrochemical redox properties of the newly synthesized polyazomethines $\mathbf{6 a}-\mathbf{e}$ based ferrocene moiety were studied by cyclic voltammetry at room temperature in (dry $\mathrm{CH}_{2} \mathrm{Cl}_{2}$ : absolute ethanol, 1:1) solutions, using glassy carbon electrode as working electrode, Pt gauze as a counter electrode and $\mathrm{Ag} / \mathrm{AgCl}$ as a reference electrode, and tetra-n-butylammonium perchlorate (TBAP) as the supporting electrolyte. The electrochemical data of the investigated compounds were compared with those of Fcmonomer 4 and Fc-model compound 5, the results are summarized in Table 3. The Cyclic voltammetric behaviour of these compounds showed one cathodic peak and the corresponding oxidation peak in the potential range of 250$650 \mathrm{mV}$ at the glassy carbon electrode. The separation of the anodic and the cathodic peak potentials, $\Delta E_{p}$, were $188,134,170,37,164,164$, and $164 \mathrm{mV}$ at $20 \mathrm{mVs}^{-1}$ for Fcmonomer 4, Fc-model 5, and Fc-polyazomethines 6a-e, respectively. These values are larger than that expected for a reversible two-electron transfer reaction, which is given by $57 / z \mathrm{mV}$, where $z$ is the number of electrons transferred in the process [39], indicating that the irreversibility of the electron-transfer process was maintained under this condition. The formal potential, $E^{0}$, taken as the average of $E_{\mathrm{pc}}$ and $E_{\mathrm{pa}}$ were $343,413,443,401,385,385$, and $428 \mathrm{mV}$ for Fc-monomer 4, Fc-model 5, and Fc-polyazomethines 6a-e, respectively. $E^{0}$ shifted to more positive potentials by ca. $100 \mathrm{mV}$ for Fc-polyazomethine $\mathbf{6 d}$ in comparing to Fc-monomer 4. This revealed that the reduction of Fcpolyazomethine $\mathbf{6} \mathbf{d}$ becomes more easily at the glassy carbon electrode. One couple of redox waves is observed clearly in the cyclic voltammograms for all compounds in the potential range ca. $0.00-1.50 \mathrm{~V}$. The couple redox waves in the potential range ca. $240-530 \mathrm{mV}$ is due to the redox process of ferrocene/ferrocenium ${ }^{+}$system. Also, there is another anodic wave for all compounds in potential range $540-650 \mathrm{mV}$, this is due to the conjugation through the conjugated aromatic system. The second anodic wave did not appear in the case of Fc-polyazomethines $\mathbf{6 b}$ and $\mathbf{c}$, due to the increasing of methyl spacer which cut the conjugation through the conjugated aromatic system, on the other hand in case of Fc-polyazomethine $6 \mathrm{e}$ this anodic wave increased because of the presence of ether aromatic linkage and the lone pairs of electron relay the conjugation through the conjugated aromatic system.

\section{Conclusion}

In this research a new interesting series of thermally stable Fcpolyazomethines $\mathbf{6 a - e}$ was synthesized via polycondensation reactions of ferrocene-dialdehyde derivative with different diamines. The ferrocene-dialdehyde was prepared through 
three- step reactions. Ferrocene was converted to ferrocenediester derivative through Gomberg's arylation reaction. Reduction of ferrocene-diester derivative using LAH converted it to ferrocene-dialcohol derivative. The latter was oxidized with activated $\mathrm{MnO}_{2}$ in dry $\mathrm{CHCl}_{3}$ to get the ferrocenedialdehyde derivative.The thermal behaviour of these new Fe-polyazomethines showed that the polymer decomposition temperature (PDT) of them did not start before $340^{\circ} \mathrm{C}$ except for Fe-polyazomethine $\mathbf{6 a}$ at $140^{\circ} \mathrm{C}$, which indicated that these new Fe-polyazomethines are thermally-stable till high temperature. Also, the electrochemical properties of these new Fe-polyazomethines were studied in comparison with both Fc-monomer $\mathbf{4}$ and Fc-model $\mathbf{5}$ by CV. SEM study of Fe-polyazomethines $\mathbf{6 b}$ indicated that its surface possesses a globular structure and for Fe-polyazomethines $\mathbf{6 d}$ the surface possesses a globular structure with some coalescence present. The research team is interested in modifying the chemical structure of these polymers aiming to improve their chemical and physical properties. This work is presently in progress.

\section{Acknowledgment}

The authors cordially thank Professor A. D. Schlüter, for helping in making some analyses through his group in ETH Zürich.

\section{References}

[1] B. M. Culbertson and C. U. Pittman, New Monomers and Polymers, Plenum Press, New York, NY, USA, 1984.

[2] C. E. Carraher, J. E. Sheats, and C. U. Pittman, Advances in Organometallic and Inorganic Polymer Science, Marcel Dekker, New York, NY, USA, 1982.

[3] Z. Zorić, V. Rapić, S. Lisac, and M. Jukić, "Ferrocene compounds. XXV: synthesis and characterization of ferrocenecontaining oligoamides, their precursors, and analogues," Journal of Polymer Science A, vol. 37, no. 1, pp. 25-36, 1999.

[4] P. Kannan, S. Senthil, R. Vijayakumar, and R. Marimuthu, "Synthesis and characterization of liquid crystalline polymers containing aromatic ester mesogen and a nonmesogenic ferrocene unit in the spacer," Journal of Applied Polymer Science, vol. 86, no. 14, pp. 3494-3501, 2002.

[5] A. S. Abd-El-Aziz, P. O. Shipman, B. N. Boden, and W. S. McNeil, "Synthetic methodologies and properties of organometallic and coordination macromolecules," Progress in Polymer Science, vol. 35, no. 6, pp. 714-836, 2010.

[6] A. S. Abd-El-Aziz, E. K. Todd, R. M. Okasha, and T. E. Wood, "Novel approach to oligomers and polymers containing neutral and cationic iron moieties within and pendent to their backbones," Macromolecular Rapid Communications, vol. 23, no. 13, pp. 743-748, 2002.

[7] S. Mehdipour-Ataei and S. Babanzadeh, "New types of heatresistant, flame-retardant ferrocene-based polyamides with improved solubility," Reactive \& Functional Polymers, vol. 67, no. 10, pp. 883-892, 2007.

[8] G. Sathyaraj, D. Muthamilselvan, M. Kiruthika, T. Weyhermüller, and B. U. Nair, "Ferrocene conjugated imidazolephenols as multichannel ditopic chemosensor for biologically active cations and anions," Journal of Organometallic Chemistry, vol. 716, pp. 150-158, 2012.
[9] J. A. Lee, B. N. Williams, K. R. Ogilby, K. L. Miller, and P. L. Diaconescu, "Synthesis of symmetrically and unsymmetrically 3,5dimethylbenzyl-substituted 1,1'-ferrocene diamines," Journal of Organometallic Chemistry, vol. 696, pp. 4090-4094, 2011.

[10] Z. Akhter, A. Nigar, M. Y. Razzaq, and H. M. Siddiqi, "Synthesis and physico-analytical studies of some novel ferrocenyl Schiff base derivatives," Journal of Organometallic Chemistry, vol. 692, no. 16, pp. 3542-3546, 2007.

[11] D. Pou, A. E. Platero-Prats, S. Pérez et al., "Schiff bases containing ferrocenyl and thienyl units and their utility in the palladium catalyzed allylic alkylation of cinnamyl acetate," Journal of Organometallic Chemistry, vol. 692, no. 22, pp. 50175025, 2007.

[12] T. R. Younkin, E. F. Connor, J. I. Henderson, S. K. Friedrich, R. H. Grubbs, and D. A. Bansleben, "Neutral single-component nickel (II) polyolefin catalysts that tolerate heteroatoms," Science, vol. 287, no. 5452, pp. 460-462, 2000.

[13] S. Yadav and R. V. Singh, "Ferrocenyl-substituted schiff base complexes of boron: synthesis, structural, physico-chemical and biochemical aspects," Spectrochimica Acta A, vol. 78, no. 1, pp. 298-306, 2011.

[14] D. J. Jones, V. C. Gibson, S. M. Green, and P. J. Maddox, "Discovery of a new family of chromium ethylene polymerisation catalysts using high throughput screening methodology," Chemical Communications, vol. 38, no. 10, pp. 1038-1039, 2002.

[15] N. Nomura, R. Ishii, M. Akakura, and K. Aoi, "Stereoselective ring-opening polymerization of racemic lactide using aluminum-achiral ligand complexes: exploration of a chain-end control mechanism," Journal of the American Chemical Society, vol. 124, no. 21, pp. 5938-5939, 2002.

[16] Y. Yoshida, J. I. Mohri, S. I. Ishii et al., "Living copolymerization of ethylene with norbornene catalyzed by bis(pyrrolide-imine) titanium complexes with MAO," Journal of the American Chemical Society, vol. 126, no. 38, pp. 12023-12032, 2004.

[17] Z. Tang, X. Chen, Y. Yang et al., "Stereoselective polymerization of rac-lactide with a bulky aluminum/schiff base complex," Journal of Polymer Science A, vol. 42, no. 23, pp. 5974-5982, 2004.

[18] P. W. Morgan, S. L. Kwolek, and T. C. Pletcher, "Aromatic azomethine polymers and fibers," Macromolecules, vol. 20, no. 4, pp. 729-739, 1987.

[19] T. Olinga, O. Inganäs, and M. R. Andersson, "Synthesis and properties of a soluble conjugated poly(azomethine) with high molecular weight," Macromolecules, vol. 31, no. 8, pp. 26762678, 1998

[20] C. J. Yang and S. A. Jenekhe, "Conjugated aromatic polyimines. 2: synthesis, structure, and properties of new aromatic polyazomethines," Macromolecules, vol. 28, no. 4, pp. 1180-1196, 1995.

[21] U. Min and J. H. Chang, "Thermotropic liquid crystalline polyazomethine nanocomposites via in situ interlayer polymerization," Materials Chemistry and Physics, vol. 129, no. 1-2, pp. 517-522, 2011.

[22] D. Sek, B. Jarzabek, E. Grabiec et al., "A study of thermal, optical and electrical properties of new branched triphenylaminebased polyazomethines," Synthetic Metals, vol. 160, no. 19-20, pp. 2065-2076, 2010.

[23] D. Sek, A. Iwan, B. Jarzabek et al., "Hole transport triphenylamine-azomethine conjugated system: synthesis and optical, photoluminescence, and electrochemical properties," Macromolecules, vol. 41, no. 18, pp. 6653-6663, 2008.

[24] İ. Kaya, M. Yildirim, and A. Avci, "Synthesis and characterization of fluorescent polyphenol species derived from methyl 
substituted aminopyridine based Schiff bases: the effect of substituent position on optical, electrical, electrochemical, and fluorescence properties," Synthetic Metals, vol. 160, no. 9-10, pp. 911-920, 2010.

[25] M. Yildirim and İ. Kaya, "Synthesis and characterization of a novel kind soluble, conjugated, and fluorescent chelate polymer containing fluorene ring in the backbone: optical, electrical, and electrochemical properties," Synthetic Metals, vol. 161, no. 1-2, pp. 13-22, 2011.

[26] S. C. Ng, H. S. O. Chan, P. M. L. Wong, K. L. Tan, and B. T. G. Tan, "Novel heteroarylene polyazomethines: their syntheses and characterizations," Polymer, vol. 39, no. 20, pp. 4963-4968, 1998.

[27] A. Iwan, M. Palewicz, A. ChuchmaThla et al., "Opto(electrical) properties of new aromatic polyazomethines with fluorene moieties in the main chain for polymeric photovoltaic devices," Synthetic Metals, vol. 162, no. 1-2, pp. 143-153, 2012.

[28] S. Destri, I. A. Khotina, and W. Porzio, "3-Hexyl tetrasubstituted sesquithienylene-phenylene polyazomethines with high molecular weight. Mechanistic considerations," Macromolecules, vol. 31, no. 4, pp. 1079-1086, 1998.

[29] A. Iwan, M. Palewicz, A. Sikora et al., "Aliphatic-aromatic poly(azomethine)s with ester groups as thermotropic materials for opto(electronic) applications," Synthetic Metals, vol. 160, no. 17-18, pp. 1856-1867, 2010.

[30] J. C. Hindson, B. Ulgut, R. H. Friend et al., "All-aromatic liquid crystal triphenylamine-based poly(azomethine)s as hole transport materials for opto-electronic applications," Journal of Materials Chemistry, vol. 20, no. 5, pp. 937-944, 2010.

[31] L. Marin, E. Perju, and M. D. Damaceanu, "Designing thermotropic liquid crystalline polyazomethines based on fluorene and/or oxadiazole chromophores," European Polymer Journal, vol. 47, no. 6, pp. 1284-1299, 2011.

[32] E. C. Buruiana, M. Olaru, and B. C. Simionescu, "Synthesis and properties of some new polyazomethine-urethanes," European Polymer Journal, vol. 38, no. 6, pp. 1079-1086, 2002.

[33] B. Jarzabek, J. Weszka, B. Hajduk, J. Jurusik, M. Domanski, and J. Cisowski, "A study of optical properties and annealing effect on the absorption edge of pristine- and iodine-doped polyazomethine thin films," Synthetic Metals, vol. 161, no. 11-12, pp. 969-975, 2011.

[34] A. A. O. Sarhan and T. Izumi, "Design and synthesis of new functional compounds related to ferrocene bearing heterocyclic moieties: a new approach towards electron donor organic materials," Journal of Organometallic Chemistry, vol. 675, no. 12, pp. 1-12, 2003.

[35] S. H. Hsiao and G. S. Liou, "A new class of aromatic poly(1,3,4-oxadiazole)s and poly(amide-1,3,4-oxadiazole)s containing (naphthalenedioxy)diphenylene groups," Polymer Journal, vol. 34, no. 12, pp. 917-924, 2002.

[36] N. S. Al-Muaikel, K. I. Aly, and M. A. Hussein, "Synthesis, characterization and antimicrobial properties of new poly(etherketone)s and copoly(ether-ketone)s containing diarylidenecycloalkanone moieties in the main chain," Journal of Applied Polymer Science, vol. 108, no. 5, pp. 3138-3147, 2008.

[37] M. Şenel, E. Çevik, and M. F. Abasiyanik, "Amperometric hydrogen peroxide biosensor based on covalent immobilization of horseradish peroxidase on ferrocene containing polymeric mediator," Sensors and Actuators B, vol. 145, no. 1, pp. 444-450, 2010.
[38] A. Xiao, Z. Li, S. Zhou et al., "Synthesis, electrochemical behaviors and anion recognition of a novel star-[Polystyrene$b$-poly(ferrocenyloxy ethyl acrylate) $]_{6}$ with hexafunctional cyclotriphosphazene core," Polymer, vol. 51, no. 5, pp. 521-525, 2012.

[39] P. Hemmerich, C. Veeger, and H. C. Wood, "Progress in the chemistry and molecular biology of flavins and flavocoenzymes," Angewandte Chemie-International Edition, vol. 4, no. 8, pp. 671-687, 1965. 

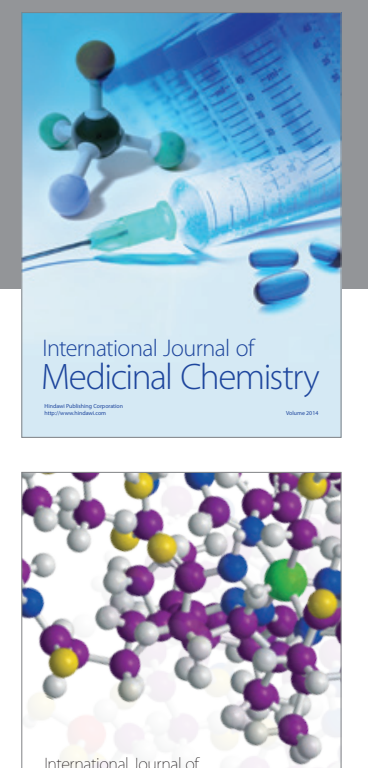

\section{Carbohydrate} Chemistry

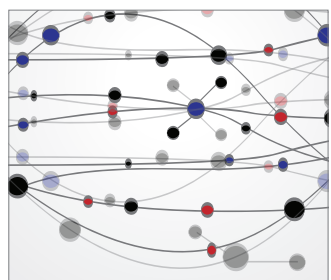

The Scientific World Journal
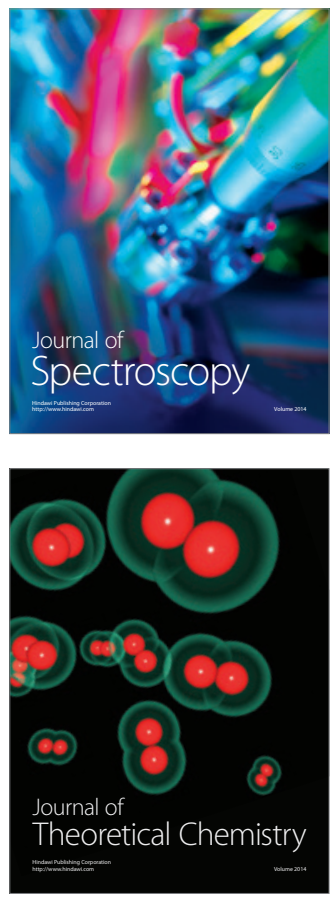
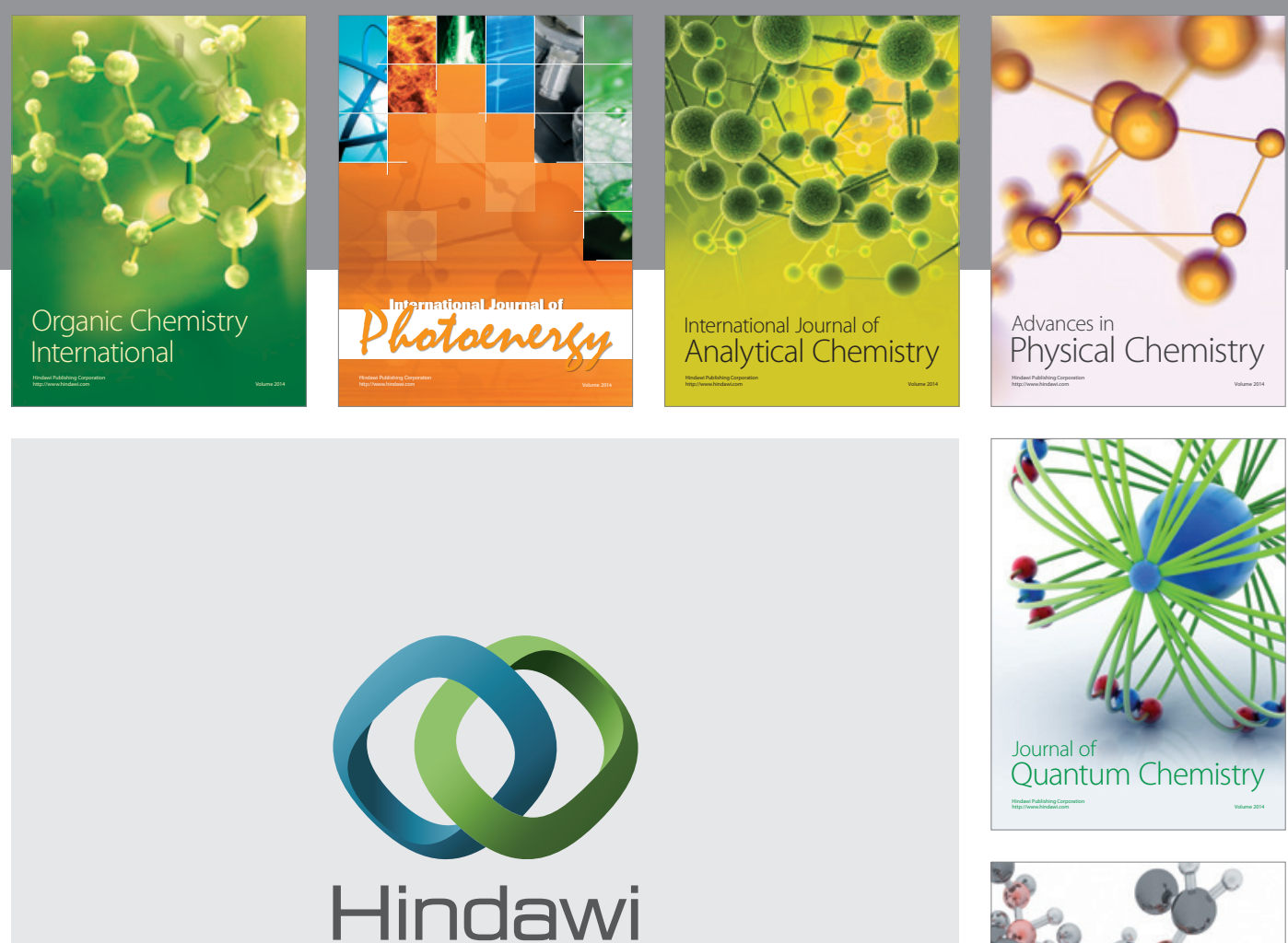

Submit your manuscripts at

http://www.hindawi.com

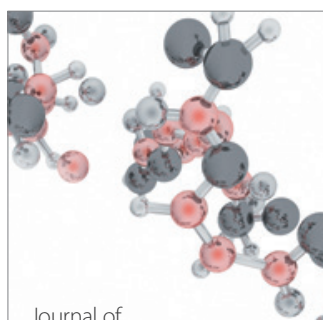

Analytical Methods

in Chemistry

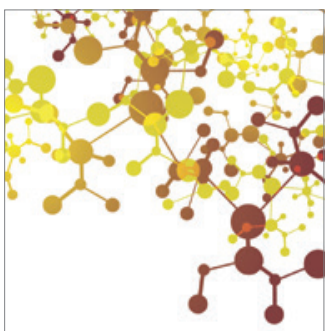

Journal of

Applied Chemistry

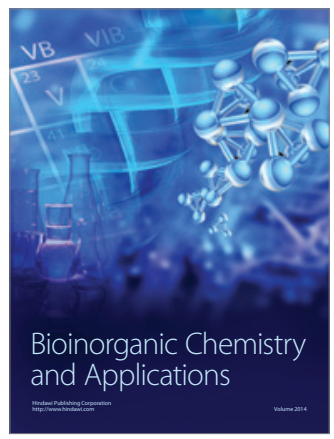

Inorganic Chemistry
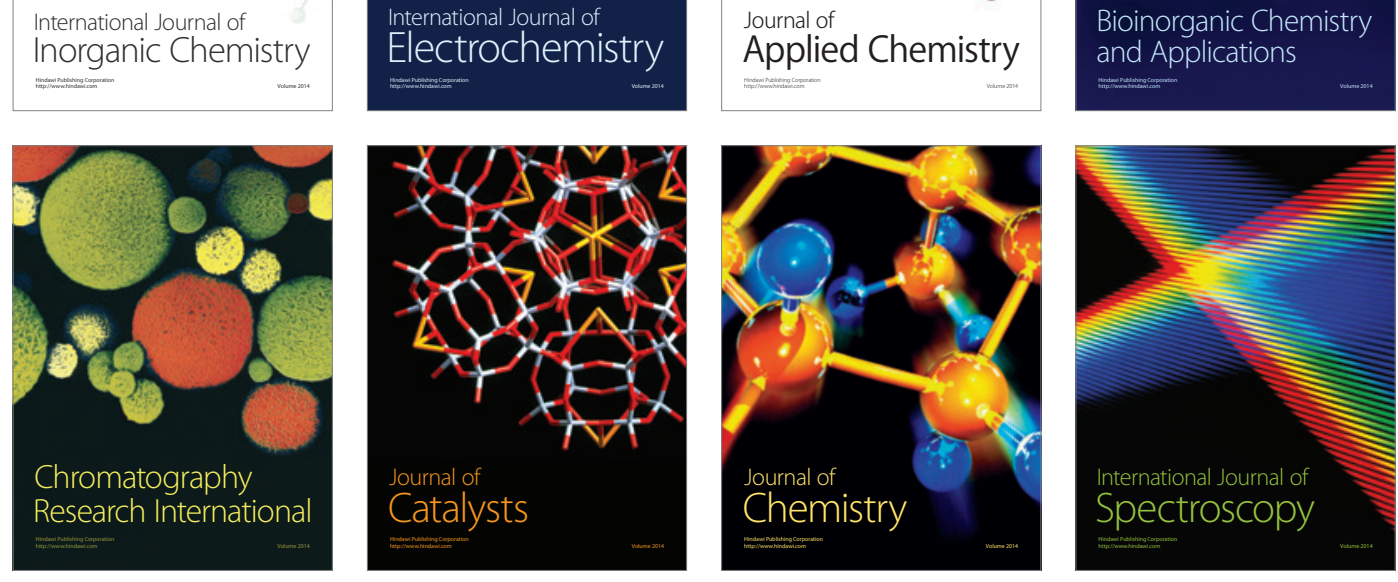